\section{Storage Humidity and Temperature Affect Dormancy Loss and Viability of Tanglehead (Heteropogon contortus) Seeds}

\author{
Orville C. Baldos ${ }^{1}$ and Joseph DeFrank \\ Department of Tropical Plant and Soil Sciences, University of Hawaii \\ at Manoa, St. John Plant Science Lab 102, 3190 Maile Way, Honolulu, \\ HI 96822
}

\section{Matthew Kramer}

U.S. Department of Agriculture Agricultural Research Service, 10300 Baltimore Avenue, Building 005 BARC-WEST, Beltsville, MD 20705

\section{Glenn S. Sakamoto}

U.S. Department of Agriculture Natural Resources Conservation Service, Hoolehua Plant Materials Center, 4101 Maunaloa Highway, P.O. Box 236, Hoolehua, HI 96729

\section{Additional index words. dry after-ripening, piligrass, speargrass, tetrazolium test}

\begin{abstract}
Tanglehead (Heteropogon contortus) is a drought- and fire-tolerant native Hawaiian grass that possesses seed dormancy on shedding. Although a dry after-ripening period is known to break dormancy, specific storage conditions to optimize this are not known. This study examined the effects of storage temperature and equilibrium relative humidity (eRH) on tanglehead seed dormancy loss and viability. Fresh seeds harvested in Mar. and Oct. 2011 were stored for 30 days in three eRH levels $(12 \%, 50 \%$, and $75 \%)$ and then incubated for $0,1,3,6,9$, and 12 months at three temperatures [10, 20 (ambient in laboratory), and $\left.30{ }^{\circ} \mathrm{C}\right]$. The eRHs were maintained during incubation by sealing seeds in airtight packages. Seed germination and tetrazolium tests were conducted after each incubation period to determine dormancy loss and seed viability. Analysis of germination and seed viability data indicated a significant interaction among $\mathrm{eRH}$, storage temperature, incubation period, and seed harvest month. Storage at $12 \% \mathrm{eRH}$ and $30{ }^{\circ} \mathrm{C}$ for 12 months optimized dormancy loss of tanglehead seeds. Seeds remained viable in all eRH and temperature combinations except those stored at either $75 \%$ eRH and $20{ }^{\circ} \mathrm{C}$ or $75 \%$ eRH and $30{ }^{\circ} \mathrm{C}$. In these treatment combinations, significant seed deterioration and loss of viability were recorded. Harvest time (i.e., harvest month) within the year also affected the rate of dormancy loss of seeds. March-harvested seeds achieved maximum dormancy loss 3 months earlier than seeds harvested in October.
\end{abstract}

Received for publication 19 June 2014. Accepted for publication 13 Aug. 2014.

This work was supported by a grant from the Hawaii Department of Transportation.

We thank David Duvauchelle, Keni Reyes, and Andres Juario for assisting us in harvesting tanglehead seeds used in this study. We also thank Dr. Teresita Amore and Peter Toves for providing access to incubators, Dr. Andrew Kaufman and Dr. Theodore Radovich for access to weighing scales, and Kai Umeda for assisting in data collection.

This paper is a portion of a $\mathrm{PhD}$ dissertation submitted by Orville C. Baldos at the University of Hawaii at Manoa.

Mention of a trademark, company, or proprietary name does not constitute an endorsement, guarantee, or warranty by the University of Hawaii, the USDA, nor the Natural Resources Conservation Service (NRCS) or its employees and does not imply recommendation to the exclusion of other suitable products or companies.

${ }^{1}$ To whom reprint requests should be addressed; e-mail obaldos@hawaii.edu. projects. Tanglehead (Heteropogon contortus) is one of several native Hawaiian species used for re-vegetation that requires further study in these areas to facilitate its use in large-scale plantings.

Tanglehead is a drought-tolerant, perennial C4 bunchgrass that grows 0.4 to $1.0 \mathrm{~m}$ high (Wagner et al., 1999). It is a widely distributed grass species throughout the dry tropical and subtropical grasslands of the world (Carino, 1999; Carino and Daehler, 1999; Tothill, 1968). In Hawaii, it is found on all main islands, usually on dry rocky cliffs, ledges, or slopes near the ocean and from elevations ranging from sea level to $700 \mathrm{~m}$ (Wagner et al., 1999). As a result of its adaptability to low rainfall, low fertility soils (USDA-NRCS, 2007), and inherent cultural and ecological value (Daehler and Goergen, 2005), tanglehead is considered an important re-vegetation and restoration species in Hawaii.

A major constraint on the use of tanglehead in restoration and re-vegetation is its seed dormancy. Freshly harvested seeds do not germinate or have very low (less than $10 \%$ ) germination. To relieve tanglehead seed dormancy, seeds can be scarified, treated with germination stimulants, or dry after-ripened. Scarification has been reported to relieve dormancy of tanglehead seeds. Studies conducted by the Kew Royal Botanic Gardens (2014) has shown high percent germination ( $77 \%$ to $100 \%$ germination) by chipping or partial removal of the covering structure. In contrast, scarification studies conducted by Baldos (2013) reported marginal to moderate dormancy relief. Removal of the husk (i.e., naked caryopsis) resulted in low and inconsistent germination $(1.0 \%$ to $16.5 \%$ germination), whereas nicking to expose the embryo resulted in partial dormancy release $(19.5 \%$ to $30.0 \%$ germination).

Aside from seed scarification, the application of germination stimulants such as gibberellic acid, aerosol smoke, food-grade liquid smoke, and smoke-infused water has been shown to relieve tanglehead seed dormancy. The application of a $1 \%$ solution of gibberellic acid can result in partial (Baldos et al., 2011) to complete dormancy release (Tothill, 1977). Application of cool aerosol smoke improved tanglehead seed germination by three to four times that of the untreated control (Campbell, 1995; Campbell et al., 1996). One-month-old seeds treated with a $1 \% \mathrm{v} / \mathrm{v}$ dilution of food-grade liquid smoke exhibited the highest percent germination $(40 \%)$ in contrast with the control $(0.5 \%$ germination) and the $1 \%$ gibberellic acid-treated seeds ( $20 \%$ germination) (Baldos et al., 2011). Water infused with smoke from burning tanglehead plant material resulted in $40 \%$ to $60 \%$ germination, whereas untreated seeds exhibited less than $5 \%$ germination (Baldos, 2013).

Dry storage (i.e., dry after-ripening) is a very effective means of breaking tanglehead seed dormancy. Seeds that have undergone a dry after-ripening period exhibit faster germination rates (Tothill, 1977) and 
high percent germination ( $80 \%$ to $90 \%)$ (Daehler and Goergen, 2005; Tothill, 1977). To break seed dormancy, tanglehead seeds must be kept in dry storage (at room temperature) for 6 to 12 months (Daehler and Goergen, 2005; Pater, 1993; Tothill, 1977; USDA-NRCS, 2007). Although dry after-ripening after drying is known to remove seed dormancy and subsequently improve germination, storage conditions to optimize this process for tanglehead seeds have yet to be determined.

Temperature and relative humidity are important storage conditions that affect the rate of seed dormancy loss as well as seed viability loss in a number of species (Baskin and Baskin, 1979; Bazin et al., 2011; Commander et al., 2009; Foley, 1994, 2008; Leopold et al., 1988; Probert, 2000; Steadman et al., 2003). Temperature is a well-known environmental factor that affects the rate of dry after-ripening (Iglesias-Fernandez et al., 2011). The application of heat during the dry after-ripening period typically accelerates dormancy loss, whereas dry storage at low temperatures tends to slow down or inhibit dormancy loss (Bannon et al., 1978; Cohn and Hughes, 1981; Reddy et al., 1985; Roberts, 1988; Steadman et al., 2003).

Relative humidity also plays a role in both the loss of seed dormancy and seed viability through seed moisture content. Together with temperature, seed moisture content influences dry after-ripening rates (Foley, 2008; Iglesias-Fernandez et al., 2011; Probert, 2000). Studies conducted on a number of species indicate that a specific range of seed moisture content is required for accelerated dry after-ripening at high temperatures (Baskin and Baskin, 1979; Bazin et al., 2011; Commander et al., 2009; Leopold et al., 1988; Steadman et al., 2003). Above or below this species-specific critical moisture threshold value, dormancy loss from dry after-ripening can be inhibited or delayed (Bewley and Black, 1994; Finch-Savage and Leubner-Metzger, 2006; Iglesias-Fernandez et al., 2011). Aside from seed dormancy loss, both temperature and seed moisture content can also impact the viability of dry-stored seeds. Storage at low temperatures and low seed moisture content generally maintains seed viability (Copeland and McDonald, 2001). In contrast, storage at high temperatures and high seed moisture content results in decreased seed viability as a result of accelerated aging (Copeland and McDonald, 2001). The objective of this study was to evaluate the effects of storage eRH, storage temperature, incubation period, and time of year (i.e., season) harvest on loss of seed dormancy and seed viability of tanglehead.

\section{Materials and Methods}

\section{Seed source}

Freshly harvested seeds of a Kahoolawe Island source-identified natural germplasm (Accession \# 9079683, HA-5748) were used for the study. Using a self-propelled combine harvester (Massey Ferguson MF-17/19; Kincaid Equipment Manufacturing, Haven, $\mathrm{KS}$ ), the seeds were mechanically harvested from irrigated field plantings maintained at the U.S. Department of Agriculture-Natural Resources Conservation Service (USDA-NRCS) Plant Materials Center on the island of Molokai (lat. $21^{\circ} 8^{\prime} 33.7842^{\prime \prime} \mathrm{N}$, long. $157^{\circ} 6^{\prime} 3.369^{\prime \prime} \mathrm{W}$ ) After harvesting, the seeds were immediately transported to the University of Hawaii at Manoa campus on Oahu for cleaning. Seeds were air-dried for $9 \mathrm{~d}$ and passed through an air-blast seed cleaner (Almaco, Nevada, IA) to remove chaff, awns, and empty seeds.

Two seed batches were harvested and identically prepared for the study. Seeds that were harvested on 22 Mar. 2011 were used for the first trial (subsequently referred to as the March seed batch), whereas seeds harvested on 27 Oct. 2011 comprised the October seed batch. Climate data and growing conditions of the two seed batches were noted.

Before eRH conditioning, $2 \mathrm{~g}$ of seeds $(\approx 1120$ seeds) were placed in each of the 252 unsealed foil barrier packets (Seed Savers Exchange, Decorah, IA) and used in each trial (seed batch). After eRH conditioning, foil packets were sealed and incubated in one of three temperature-controlled chambers for $0,1,3,6,9$, and 12 months.

\section{Experimental design and treatment application}

The experimental design had three factors and was replicated at two harvest dates (March and October-harvested seeds). The main effects were eRH $(75 \%$ eRH, 50\% $\mathrm{eRH}$, and $12 \% \mathrm{eRH}$ ), storage temperature $\left[10^{\circ} \mathrm{C}\right.$ (cold storage temperature), $20^{\circ} \mathrm{C}$ (airconditioned laboratory temperature), and $30^{\circ} \mathrm{C}$ (incubator temperature)], and the length of storage/incubation $(0,1,3,6,9$, and 12 months). The eRH treatments were the first to be applied to the seeds by storing the unsealed packets containing the seeds for $28 \mathrm{~d}$ in three desiccators containing different saturated salt solutions (Commander et al., 2009; Turner et al., 2009). Saturated salt solutions of lithium chloride $\left(\mathrm{LiCl} \cdot \mathrm{H}_{2} \mathrm{O}\right)$, calcium nitrate $\left[\mathrm{Ca}\left(\mathrm{NO}_{3}\right)_{2}\right]$, and sodium chloride $(\mathrm{NaCl})$ were used to establish and then maintain humidities of $12 \%, 50 \%$, and $75 \% \mathrm{eRH}$, respectively, at $25{ }^{\circ} \mathrm{C}$ (Turner et al., 2009; Winston and Bates, 1960). After $28 \mathrm{~d}$ the packets were removed from the eRH chambers and sealed using a thermal impulse heat sealer (Uline, Pleasant Prairie, WI) to maintain the designated humidity/seed moisture treatment. Before the application of the three storage temperature treatments, 36 sealed packets were randomly sampled to determine the seed moisture, viability (i.e., tetrazolium test), and germination at Month 0 (i.e., post-eRH conditioning). The rest of the packets were portioned and incubated at $10{ }^{\circ} \mathrm{C}$ (refrigerator), $20{ }^{\circ} \mathrm{C}$ (ambient laboratory temperature), or $30^{\circ} \mathrm{C}$ (incubator) for 1 , $3,6,9$, and 12 months.

\section{Seed moisture determination,} germination, and seed viability tests

Tests were conducted at the end of each incubation period to monitor seed moisture, dormancy loss, and seed viability/deterioration. Seed moisture determination was done using the gravimetric method. A 1-g seed sample from a seed packet $(n=4)$ was dried for 17 $\mathrm{h}$ in a drying oven (Quincy Laboratory, Inc., Chicago, IL) with temperature set at $103{ }^{\circ} \mathrm{C}$ (Commander et al., 2009; ISTA, 1996). Seed moisture was calculated using the formula:

$$
\begin{aligned}
& \text { Percent seed moisture (dry weight basis) } \\
& =\frac{\text { Fresh weight }- \text { Oven dry weight }}{\text { Oven dry weight }} \times 100 .
\end{aligned}
$$

Germination tests were conducted with four replicates of 50 seeds sown in $100 \mathrm{~mm} \times$ $100 \mathrm{~mm} \times 15-\mathrm{mm}$ square polystyrene petri dishes (Fisherbrand; Thermo Fisher Scientific, Inc., Waltham, MA). The petri dishes were lined with two layers of filter paper (Whatman \#3; Whatman International, Maidstone, U.K.) and moistened with $3 \mathrm{~mL}$ distilled water. Edges of the petri dish were sealed with parafilm (SPI Supplies, West Chester, PA). The seeds in the petri dishes were germinated in a $30^{\circ} \mathrm{C}$ (Tothill, 1977) incubator under dark conditions. To prevent drying during the germination period, the petri dishes were moistened as needed with distilled water. Seed germination was observed regularly under lighted conditions for $20 \mathrm{~d}$. The total number of seeds that germinated at the end of $20 \mathrm{~d}$ was recorded. Seeds were counted as germinated when at least $1 \mathrm{~mm}$ of the radicle had emerged.

Tetrazolium tests for seed viability were also conducted at the end of each incubation period. This stain-based test is a widely recognized and accurate means of estimating seed viability and is a routine test in many seed testing facilities (Copeland and McDonald, 2001), detecting the presence of dehydrogenase activity in actively respiring viable seed tissues (Elias et al., 2012).

Four replicates of 50 seeds were soaked in distilled water overnight to activate seed enzymes as well as to facilitate seed softening for cutting. After soaking, the imbibed seeds were cut longitudinally through the middle of the embryonic axis (Peters, 2000). Half of the cut seed was placed in a $20-\mathrm{mL}$ scintillation vial. The vial was filled with $3 \mathrm{~mL}$ of $1 \%$ tetrazolium chloride (Sigma Aldrich, St. Louis, MO) solution and incubated in the dark at $27{ }^{\circ} \mathrm{C}$ for $5 \mathrm{~h}$ to allow staining. The stained seeds were washed with distilled water, arranged in a petri dish lined with moistened filter paper, and observed under a dissecting microscope. Seeds were counted as viable based on staining patterns. Fully stained embryos were recorded as viable seed, whereas partially stained embryos or stained whole seeds (caused by fungal contamination of both the embryo and endosperm) were considered non-viable. The percentage of viable seeds was recorded.

\section{Statistical analyses}

Percent moisture. Analysis of variance (PROC GLM in SAS 9.3; SAS Institute Inc., Cary, NC) was conducted on the seed moisture data to monitor for any significant 
changes in seed moisture during the experiment. Before analysis, percent moisture content values were converted into decimal forms (i.e., grams $\mathrm{H}_{2} \mathrm{O}$ per grams dry weight) and then square root transformed to stabilize variances, because the range of seed moisture values was between $0 \%$ and $30 \%$ (Gomez and Gomez, 1984). The Tukey-Kramer means separation method $(P<0.05)$ was used to separate the means of treatment combinations. For ease of interpretation, the means and $95 \%$ confidence intervals were back-transformed to percent moisture (dry weight basis) using the equation: Percent moisture (dry weight basis) $=$ $100\left(p^{2}\right)$, where $p$ is the square root-transformed decimal form of seed moisture (i.e., grams $\mathrm{H}_{2} \mathrm{O}$ per grams dry weight).

Percent germination. Two types of statistical testing (i.e., Fisher's exact test and generalized linear mixed modeling) were used to analyze the germination data. Fisher's exact test was used to compare monthly differences in the proportion of seeds that germinated from the March and October seed harvests. The total number of germinated and non-germinated seeds in each seed batch and in each incubation month was recorded, regardless of the humidity and temperature treatments. The association between the incidence of germination and seed batch at each incubation month was examined using a two $\times$ two contingency table (Pagano and Gauvreau, 2000).

A generalized linear mixed model (GLMM), using the logit link for binomial distributions, was used to analyze treatment combinations exhibiting consistent germination (i.e., non-zero germination) (Reeve and Strom, 2004) for both seed batches (i.e., seeds stored at $12 \%$ and $50 \% \mathrm{eRH}$; at 20 and $30{ }^{\circ} \mathrm{C}$ and incubated from 6 to 12 months). GLMM analysis used PROC GLIMMIX (SAS Version 9.3; SAS Institute Inc.). GLMMs allow modeling of data exhibiting a non-normal distribution or heterogeneous variances and for including both fixed and random effects (Sileshi, 2012). The binomial response distribution is appropriate for studies involving proportion-based germination data (Pendleton et al., 2012; Willenborg et al., 2005).

In this GLMM analysis, the seed packets are random effects. Because biological binomial data are often over-dispersed [that is, variances are greater than the assumed $n(p)(1-p)$, where $n$ is the sample size and $p$ the proportion of interest], additional interactions between the packet random effects and fixed effects were included as needed (Stroup, 2013).

Seed viability data. A GLMM was also used to analyze the tetrazolium viability data. Treatment combinations exhibiting zero means were also removed before statistical analysis (Reeve and Strom, 2004). For this data set, only the Oct. $2011,75 \% \mathrm{eRH} / 30{ }^{\circ} \mathrm{C} / 9$-month treatment combination was removed. We used PROC GLIMMIX (SAS Version 9.3; SAS Institute Inc.) using a logit link to model the dependent variable (proportion viable).

Means on the logit scale were separated using Tukey-Kramer grouping $(P<0.05)$.
For ease of interpretation, mean percent germination and viability before entry in tables and figures were back-transformed from the logit scale using the equation: $a=100\left(\frac{e^{x}}{1+e^{x}}\right)$, where $x$ is the logit estimate from the model, $e$ is the exponential function, and $a$ is the mean germination or viability percentage after back transformation.

\section{Results}

Growing conditions of the seed batches. Climate data obtained during growth and development of the seed batches indicated distinct differences in daylength, average temperatures, solar radiation, total precipitation, and growing degree-days (Table 1). There was also a difference in the length of time needed to reach seed maturity (Table 1). The Mar. 2011 seeds were harvested 111 $\mathrm{d}$ after the previous harvest event (i.e., field was cut to the ground), whereas the Oct. 2011 seeds were harvested $94 \mathrm{~d}$ after the previous harvest.

Seed moisture, viability, and percent germination after equilibration. Moisture content determination at Month 0 (i.e., end of equilibration phase, start of temperature application) indicated levels of seed moisture depending on the storage eRH. Seed moisture content of the Mar. 2011 seed batch before the application of the temperature treatments was $5.7 \%, 11.1 \%$, and $14.1 \%$ (dry weight basis) for $12 \% \mathrm{eRH}$, $50 \%$ eRH, and $75 \%$ eRH, respectively. For the Oct. 2011 seeds, the percent seed moisture content before the application of the temperature treatments was $5.7 \%$, $11.8 \%$, and $14.9 \%$ (dry weight basis) for $12 \% \mathrm{eRH}, 50 \% \mathrm{eRH}$, and $75 \% \mathrm{eRH}$, respectively. The initial/base percent viability for both batches was similar, ranging from $87.5 \%$ to $90 \%$. Percent germination data before the application of the temperature treatments indicated that the seeds were still dormant. Percent germination ranged from zero to less than $0.3 \%$ for both seed batches.

Percent moisture content. Analysis of seed moisture content indicated significant interactions among the fixed effects, although the main effect of eRH clearly dominated moisture content (Fig. 1, pooled over storage temperature). Both March and October-harvested seeds stored at $12 \% \mathrm{eRH}$ maintained a seed moisture content of $6 \%$ (dry weight basis) over the 12 -month incubation period. Moisture content of seeds stored at $50 \%$ eRH was generally maintained in both seed batches at $11 \%$ (dry weight basis) except for the Marchharvested seed stored at 6 months (Fig. 1). At this incubation period, seed moisture significantly increased to $12.6 \%$.

March-harvested seeds stored at $75 \%$ eRH exhibited the same seed moisture content $(14 \%)$ during the 12 -month incubation period (Fig. 1). In contrast, the Octoberharvested seeds exhibited a slight but significant decrease in seed moisture content during the storage period. Seed moisture content slightly decreased from $14.9 \%$ (dry weight basis) in Month 0 to $13.3 \%$ (dry weight basis) after 12 months of storage. In summary, levels obtained during the prestorage moisture conditioning phase were generally maintained throughout the storage intervals.

Percent germination over time. Fisher's exact tests conducted at each storage period detected significant differences in the germination (pooled across temperature and eRH treatments) between the March and Oct. 2011-harvested seeds (Table 2). Differences in the proportion of germinated seeds between the two seed batches were detected from 3 to 12 months in incubation. March-harvested seeds exhibited 96, 368, 403, and 433 germinated seeds (each $\mathrm{n}=$ 1800) after 3, 6, 9, and 12 months in incubation, respectively. In contrast, October-harvested seeds exhibited a significantly lower number with seven, 202, 309, and 382 seeds germinating (each $\mathrm{n}=1800$ ) after 3, 6, 9, and 12 months in incubation, respectively (Table 2). This difference in the proportion of germinated seeds indicates that the Mar. 2011 batch had a reduced depth of dormancy compared with the Oct. 2011 batch.

GLMM analysis of percent germination excluded data from treatment combinations exhibiting zero to less than $3 \%$ germination (i.e., seeds stored at $10{ }^{\circ} \mathrm{C}$, regardless of eRH and seeds stored from Months 0 to 3 at the $20^{\circ} \mathrm{C}$ and $30^{\circ} \mathrm{C}$, regardless of eRH). In both seed batches, storage at $10{ }^{\circ} \mathrm{C}$ regardless of eRH appears to maintain dormancy of tanglehead. Germination of seeds stored at this temperature generally did not improve with storage over time.

Preliminary analysis with the treatments exhibiting consistent non-zero germination indicated moderate over-dispersion of 2.61 (a value of 1 indicates no over-dispersion). This was accommodated in the analysis by including appropriate random effects in the models. The four-way interaction between all main effects was significant $(P=0.0001)$, indicating that only certain combinations

Table 1. Climate data and trends recorded during seed production and development of the Mar. and Oct. 2011 tanglehead (Heteropogon contortus) seed batches.

\begin{tabular}{lcc}
\hline Climate component & Mar. 2011 & Oct. 2011 \\
\hline Daylength & Increasing & Decreasing \\
Average temperature & $21.5{ }^{\circ} \mathrm{C}$ & $24.2{ }^{\circ} \mathrm{C}$ \\
Solar radiation & Increasing & Decreasing \\
& $\left(41\right.$ to $\left.598 \mathrm{cal} / \mathrm{cm}^{2}\right)$ & $\left(227\right.$ to $\left.653 \mathrm{cal}^{2} \mathrm{~cm}^{2}\right)$ \\
Total precipitation & $z$ & $1.2 \mathrm{~cm}$ \\
Total growing degree units & $25.9 \mathrm{~cm}$ & $935.0 \mathrm{GDU}$ \\
Maturity & $760.6 \mathrm{GDU}$ & $94 \mathrm{~d}$ \\
\hline
\end{tabular}

${ }^{\mathrm{z}}$ In addition to total precipitation, supplemental irrigation was also applied in the field. 


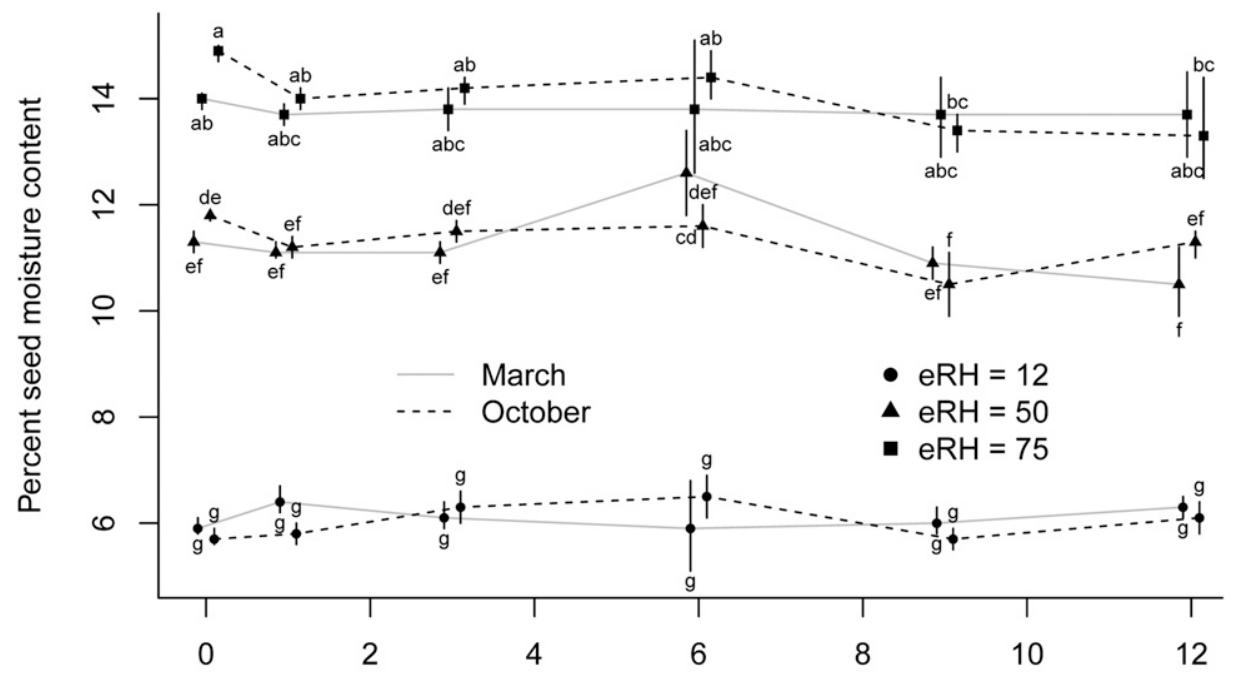

Months in incubation

Fig. 1. Monthly percent moisture content (dry weight basis, based on 1-g samples) of tanglehead (Heteropogon contortus) seeds stored at three equilibrium relative humidities (eRHs) (i.e., pooled over storage temperatures). Means separation was performed over all combinations of the three factors (i.e., like in a one-way analysis of variance). Values followed by the same letters are not significantly different as determined by Tukey's range test at $P<0.05$. Seed moisture contents, with $95 \%$ confidence intervals, are back-transformed means. Symbols and lines were shifted on the x-axis to avoid overlapping; each group of symbols is centered on its respective months in incubation.

Table 2. Contingency table at each month of incubation comparing the pooled number (i.e., pooled across storage temperature and relative humidity) of germinated and non-germinated tanglehead (Heteropogon contortus) seeds in the Mar. and Oct. 2011 seed batches.

\begin{tabular}{|c|c|c|c|c|c|c|c|}
\hline \multirow[b]{2}{*}{ Seed batch } & \multirow[b]{2}{*}{ Germination } & \multicolumn{6}{|c|}{ Months in incubation } \\
\hline & & 0 & 1 & 3 & 6 & 9 & 12 \\
\hline Mar. 2011 & Yes & 3 & 3 & 96 & 368 & 403 & 433 \\
\hline \multicolumn{2}{|c|}{$\begin{array}{l}\text { Fisher's exact test, two-tailed } P \\
\quad \text { value }\end{array}$} & $0.1249 \mathrm{NS}$ & $1.000 \mathrm{NS}$ & $0.00^{\mathrm{y}}$ & $0.00^{\mathrm{y}}$ & $0.0001^{\mathrm{y}}$ & $0.0424^{z}$ \\
\hline
\end{tabular}

${ }^{2}$ The proportion of seeds that germinated are different between the two seed batches $(P=0.05)$.

${ }^{y}$ The proportion of seeds that germinated are different between the two seed batches $(P<0.01)$.

NS = nonsignificant; the proportion of seeds that germinated are identical between the two seed batches.

of these factors produced high germination (Fig. 2). Based on percent germination data obtained from both seed batches, the optimum storage conditions for dormancy loss was at $12 \% \mathrm{eRH} / 30{ }^{\circ} \mathrm{C}$ for 12 months (Fig. 2).

Percent viability over time. Preliminary analysis indicated moderate over-dispersion of 3.53. This was accommodated in the analysis by including appropriate random effects in the models. The significant interactions among the main effects $(P<0.0001)$ suggest it is best to look at individual treatment combinations. Seeds stored at $30^{\circ} \mathrm{C}$ and at $\mathrm{eRH}=75$ for 6 months or more had particularly low viability (Fig. 3, bottom panel). Other storage eRH and temperature treatment combinations in both seed batches maintained a high percentage of viable seed over time.

\section{Discussion}

Results of the study indicated that a specific range of storage temperature and seed moisture content affects the rate of dormancy loss and viability of tanglehead seeds. Dormancy loss was hastened by increasing the storage temperature from ambient $\left(20^{\circ} \mathrm{C}\right)$ to high $\left(30{ }^{\circ} \mathrm{C}\right)$ at a narrow range of seed moisture content $(6 \%$ to $11 \%$, dry weight basis). This range of seed moisture content was within the minimum and maximum values [2.5\% to $20 \%$ (dry weight basis)] that have been reported for a number of species (Bazin et al., 2011; Foley, 1994; Leopold et al., 1988; Steadman et al., 2003). Increasing storage temperatures alleviated seed dormancy at seed moisture contents between $2.5 \%$ and $12 \%$ in sunflower (Helianthus annuus) (Bazin et al., 2011), 5\% to $20 \%$ in wild oat (Avena fatua) (Foley, 1994), and $6 \%$ to $18 \%$ in ryegrass (Lolium rigidum) (Steadman et al., 2003). In red rice (Oryza sativa), after-ripening at $25{ }^{\circ} \mathrm{C}$ was most rapid between $6 \%$ and $14 \%$ moisture content (dry weight basis) (Leopold et al., 1988).

When seed moisture contents are below the species-specific threshold, dormancy loss is halted under dry, unimbibed conditions (i.e., dry after-ripening) (Iglesias-Fernandez et al., 2011). For example, in red rice, severe inhibition of after-ripening was observed in seeds with less than 5\% moisture content (dry weight basis) (Leopold et al., 1988). In the current study, the range of seed moisture contents evaluated did not indicate a minimum threshold for inhibiting after-ripening. Instead, low temperature $\left(10^{\circ} \mathrm{C}\right)$ was responsible for preventing tanglehead seed afterripening. Low storage temperatures are known to prevent or delay seed dormancy loss of dry-stored seeds (Bazin et al., 2011; Simpson, 1990; Steadman et al., 2003). The temperature at which dormancy loss is prevented is species-specific. A number of studies have identified the temperature at which seed dormancy of certain species is maintained (i.e., critical base temperature). In red rice (Oryza sativa), storage at $-15{ }^{\circ} \mathrm{C}$ with seed moisture contents of $11 \%$ to $12 \%$ maintained dormancy for up to 1 year (Cohn and Hughes, 1981). Thermal after-ripening time models for dormancy loss in sunflower (Helianthus annuus L., cv. LG5665) and ryegrass calculated the critical base temperature at $8{ }^{\circ} \mathrm{C}$ with moisture contents above $10 \%$ (0.1 $\mathrm{g} \mathrm{H}_{2} \mathrm{O} / \mathrm{g}$ dry weight) (Bazin et al., 2011) and $5.4{ }^{\circ} \mathrm{C}$ with moisture contents between $6 \%$ and $18 \%$ (dry weight basis) (Steadman et al., 2003), respectively.

Aside from the maintenance of seed dormancy, storage at low temperature $\left(10^{\circ} \mathrm{C}\right)$, regardless of seed moisture content, also preserved viability of tanglehead seeds for at least 1 year. Similar studies have also 


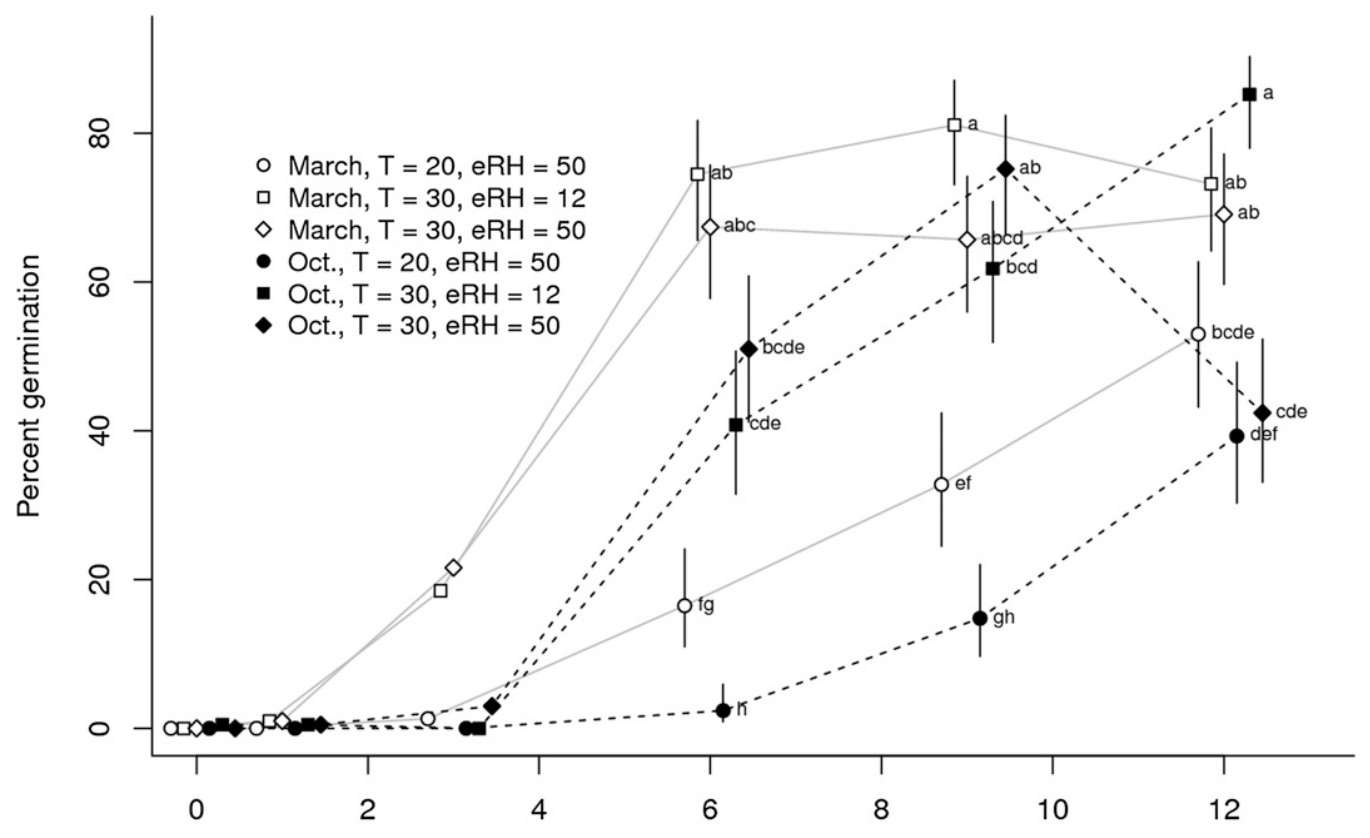

Months in incubation

Fig. 2. Percent germination of tanglehead (Heteropogon contortus) seeds harvested at different dates (i.e., Mar. and Oct. 2011) and incubated for 0, 1, 3, 6, 9, and 12 months at different equilibrium relative humidities $(\mathrm{eRHs}=12 \%$ and $50 \%)$ and storage temperatures $\left(\mathrm{T}=20\right.$ and $\left.30{ }^{\circ} \mathrm{C}\right)$. Treatment combinations exhibiting a maximum germination of $10 \%$ or less are not presented (i.e., $\mathrm{T}=10{ }^{\circ} \mathrm{C}$ at $\mathrm{eRH}=12 \%$ and $50 \%$, and $\mathrm{T}=10,20$, and $30{ }^{\circ} \mathrm{C}$ at $\mathrm{eRH}=75 \%$ ). Treatments with zero or inconsistent germination between seed harvests were also excluded in the statistical analysis. Means separation was performed over all combinations of the four factors (i.e., like in a one-way analysis of variance). Values followed by the same letters are not significantly different as determined by Tukey's range test at $P<0.05$. Percent germination values, with $95 \%$ confidence intervals, are back-transformed means. Symbols and lines were shifted on the $\mathrm{x}$-axis to avoid overlapping; each group of symbols is centered on its respective months in incubation.

recorded the maintenance of seed viability with storage at low temperatures. In leafy spurge (Euphorbia esula), storage of seeds at $5^{\circ} \mathrm{C}$ for 24 weeks did not result in loss of seed viability even at $88 \%$ relative humidity or $13 \%$ seed moisture content (dry weight basis) (Foley, 2008). Seed viability was also preserved in wild poinsettia (Euphorbia pulcherrima) seeds stored for 9 months at $5{ }^{\circ} \mathrm{C}$ with $7.7 \%$ or less seed moisture content (dry weight basis) (Bannon et al., 1978). Increasing the seed moisture content to $18.6 \%$, however, resulted in full viability loss by 6 months in storage. For most crop seeds, temperatures at 4 to $10{ }^{\circ} \mathrm{C}$ can be considered safe for short-term storage as long as the relative humidity does not exceed 70\% (Copeland and McDonald, 2001). If long-term storage is considered (i.e., 10 years or longer), seeds must be placed at a relative humidity lower than $50 \%$ and temperatures lower than $5{ }^{\circ} \mathrm{C}$ (Copeland and McDonald, 2001; Toole, 1950). Although the current study indicated that at $10{ }^{\circ} \mathrm{C}$, tanglehead dormancy and seed viability were maintained regardless of storage relative humidity, longer-term studies (greater than 1 year) are recommended to determine the optimum long-term storage conditions.

Seed moisture contents above the threshold value can also inhibit dormancy loss (Bewley and Black, 1994; Leopold et al., 1988). Higher seed moisture levels can induce secondary dormancy (Bewley and Black, 1994) and it can also increase loss of seed viability (Baskin and Baskin, 1979;
Bewley and Black, 1994; Foley, 2008; Probert, 2000). In the current study, after-ripening at 20 and $30{ }^{\circ} \mathrm{C}$ appears to be inhibited at $14 \%$ seed moisture content (dry weight basis). Percent germination in these treatment combinations was less than $10 \%$ and did not increase with storage time (data not shown). Loss of seed viability and increased incidence of mold growth also become more apparent in these treatment combinations as storage time increases. At $11 \%$ seed moisture content and $30{ }^{\circ} \mathrm{C}$, after-ripening still occurs but a decrease in seed viability is more probable with increased storage time. This was observed in October-harvested seeds incubated at these conditions for 12 months.

Aside from temperature and seed moisture effects on loss of seed dormancy and seed viability, results also indicated that the two seed batches exhibited differences in the depth of dormancy. Despite having similar percent seed viability, there were differences in the proportion of seeds that germinated in the March and October seed batches. From Month 3 to Month 12 of incubation, the March-harvested seeds consistently exhibited more germination than the October-harvested seeds.

In addition to the differences observed in the total number of seeds germinated from each seed batch, differences in the depth of dormancy can also be detected in the time period where optimum dormancy loss was achieved. In the Mar. 2011 seed batch, maximum germination was observed as early as 6 months with storage at $30^{\circ} \mathrm{C}$ in either
$12 \%$ eRH ( $6 \%$ moisture, dry weight basis) or $50 \%$ eRH (11\% moisture, dry weight basis). For the Oct. 2011 seed batch, the maximum germination was recorded after 9 months in storage at $30{ }^{\circ} \mathrm{C}$ and $50 \%$ eRH $(11 \%$ seed moisture, dry weight basis) and after 12 months with storage at $30{ }^{\circ} \mathrm{C}$ and $12 \% \mathrm{eRH}$ ( $6 \%$ seed moisture, dry weight basis).

Seasonal differences in depth of seed dormancy can be attributed to the growing conditions seeds received during their development and can include daylength, light quality, mineral nutrition, soil moisture, temperature, and physiological age of mother plants (Baskin and Baskin, 2001; Simpson, 1990). Although these differences in growing conditions might have affected the dormancy status of each seed batch, more in-depth studies focusing on each of these environmental factors are needed to confirm and quantify these time-of-year effects on the depth of seed dormancy.

In addition to practical applications in restoration, re-vegetation, and seed storage, the temperature and relative humidity effects described in this study may also help explain the phenology and seed dormancy loss of tanglehead under natural conditions in Hawaii. The dry leeward side of the islands where tanglehead thrives is seasonally dry and receives an annual rainfall of $1200 \mathrm{~mm}$ or less (Goergen and Daehler, 2001; Wagner et al., 1999). Much of the annual rainfall in these areas occurs primarily during the winter months (October to April) (Goergen and Daehler, 2001). Rains during the winter 


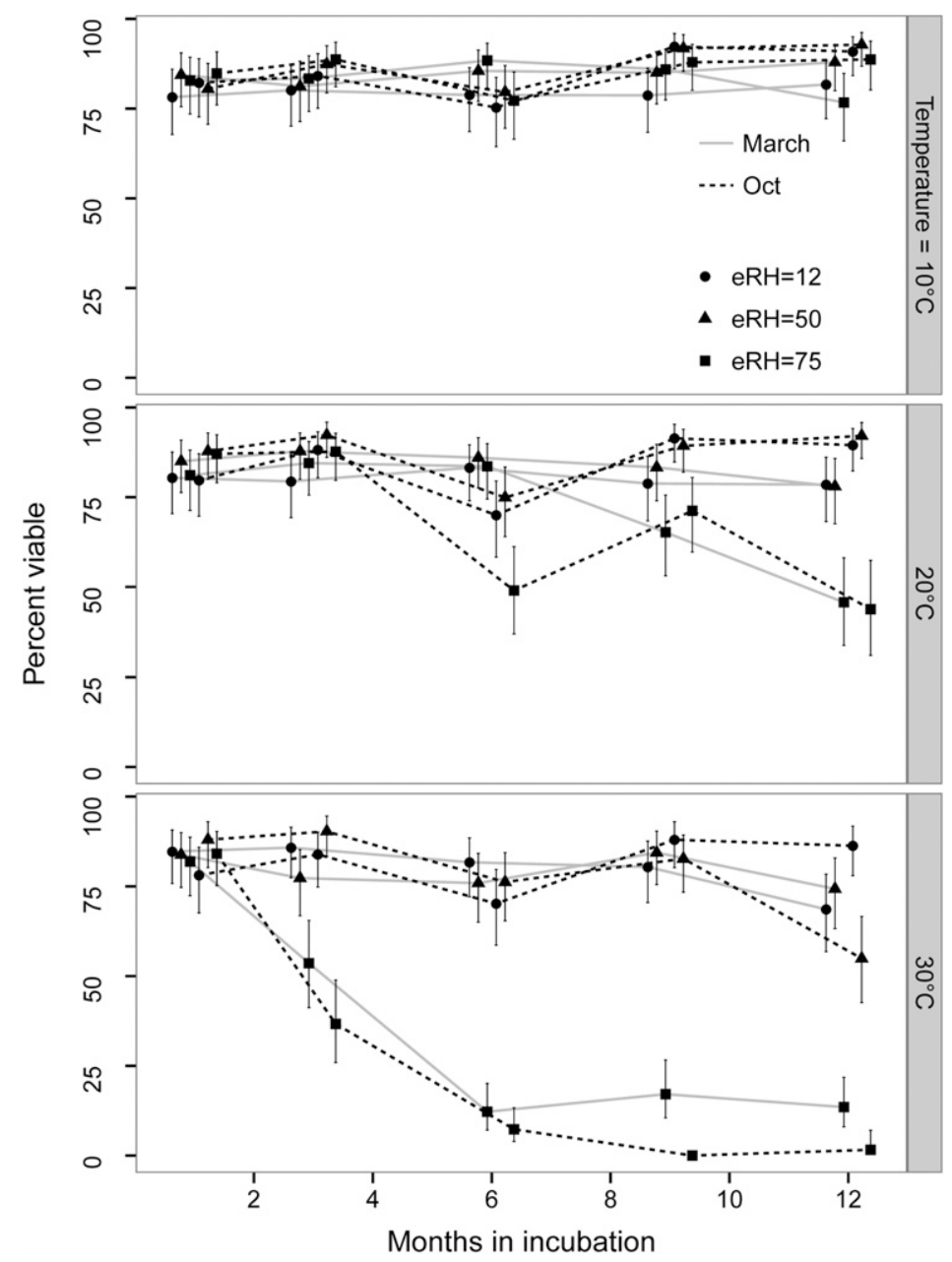

Fig. 3. Percent seed viability of tanglehead (Heteropogon contortus) harvested at different dates (i.e., Mar. and Oct. 2011) and incubated for $0,1,3,6,9$, and 12 months at different equilibrium relative humidities (eRHs $=12 \%, 50 \%$, and $75 \%$ ) and storage temperatures $\left(\mathrm{T}=10,20\right.$, and $\left.30^{\circ} \mathrm{C}\right)$. Seed moisture contents, with $95 \%$ confidence intervals, are back-transformed means. Symbols and lines were shifted on the $\mathrm{x}$ axis to avoid overlapping; each group of symbols is centered on its respective months in incubation.

season provide adequate soil moisture for tanglehead to flower and set seeds. Seeds produced during the winter months are shed and undergo a drying period as the summer season approaches (May to September). During the summer season, the shed seeds are likely exposed to hot and dry conditions, which are conducive for dormancy loss. By the time the next winter rains arrive, the seeds have already lost dormancy and are ready to germinate.

In summary, this study showed that storage temperature, relative humidity, and storage duration impacted dormancy loss and viability of tanglehead seeds. For optimum dormancy loss, seeds must be stored at $30{ }^{\circ} \mathrm{C}$ and $12 \%$ eRH ( $6 \%$ seed moisture, dry weight basis) for 12 months. Storage at $10{ }^{\circ} \mathrm{C}$, regardless of eRH, maintained dormancy and viability for up to 1 year. Seed viability was maintained for up to 1 year with storage at ambient $\left(20^{\circ} \mathrm{C}\right)$ and high $\left(30^{\circ} \mathrm{C}\right)$ temperatures as long as the relative humidity was maintained at $12 \%(6 \%$ seed moisture content).

\section{Literature Cited}

Baldos, O. 2013. Seed dormancy, smokestimulated germination and harvest timing of pili grass (Heteropogon contortus), a native Hawaiian grass with potential for expanded use. PhD diss., Univ. of Hawaii at Manoa, Honolulu, HI. Abstr. 3585985.

Baldos, O., J. DeFrank, and G.S. Sakamoto. 2011. Improving germination of piligrass (Heteropogon contortus) seeds using liquid smoke flavoring. HortScience 46:S312 (abstr.).

Bannon, J., J. Baker, and R. Rogers. 1978. Germination of wild poinsettia (Euphorbia heterophylla). Weed Sci. 26:221-225.

Baskin, C.C. and J.M. Baskin. 2001. Causes of within-species variations in seed dormancy and germination characteristics, p. 181-238. In: Seeds: Ecology, biogeography, and evolution of dormancy and germination. Academic Press, San Diego, CA.

Baskin, J.M. and C.C. Baskin. 1979. Effect of relative humidity on afterripening and viability in seeds of the winter annual Draba verna. Bot. Gaz. 140:284-287.

Bazin, J., D. Batlla, S. Dussert, H. El-MaaroufBouteau, and C. Bailly. 2011. Role of relative humidity, temperature, and water status in dormancy alleviation of sunflower seeds during dry after-ripening. J. Expt. Bot. 62:627-640.

Bewley, J.D. and M. Black. 1994. Dormancy and the control of germination, p. 199-271. Seeds. Physiology of development and germination. Plenum Press, New York, NY.
Campbell, S.D. 1995. Plant mechanisms that influence the balance between Heteropogon contortus and Aristida ramosa in spring burnt pastures. PhD diss., Univ. of Queensland, Queensland, Australia.

Campbell, S.D., L.M. Bahnisch, and D.M. Orr. 1996. Fire directly promotes the germination of dormant speargrass (Heteropogon contortus) seed. Trop. Grassl. 30:162.

Carino, D.A. and C.C. Daehler. 1999. Genetic variation in an apomictic grass, Heteropogon contortus, in the Hawaiian Islands. Mol. Ecol. 8:2127-2132.

Carino, D.A.M. 1999. Competitive ability, susceptibility to invasion, and genetic variation of pili grass (Heteropogon contortus). Univ. of Hawaii at Manoa, Honolulu, HI. MS Microfilm S38627.

Cohn, M.A. and J.A. Hughes. 1981. Seed dormancy in red rice (Oryza sativa) I. Effect of temperature on dry-afterripening. Weed Sci. 29:402-404.

Commander, L.E., D.J. Merritt, D.P. Rokich, and K.W. Dixon. 2009. The role of after-ripening in promoting germination of arid zone seeds: A study on six Australian species. Bot. J. Linn. Soc. 161:411-421.

Copeland, L.O. and M.B. McDonald. 2001. Principles of seed science and technology. Kluwer Academic Publishers, Norwell, MA.

Daehler, C.C. and E.M. Goergen. 2005. Experimental restoration of an indigenous Hawaiian grassland after invasion by buffel grass (Cenchrus ciliaris). Restor. Ecol. 13:380-389.

Elias, S.G., L.O. Copeland, M.B. McDonald, and R.Z. Baalbaki. 2012. Seed testing: Principles and practices. Michigan State Univ. Press, East Lansing, MI.

Finch-Savage, W.E. and G. Leubner-Metzger. 2006. Seed dormancy and the control of germination. New Phytol. 171:501-523.

Foley, M.E. 1994. Temperature and water status of seed affect afterripening in wild oat (Avena fatua). Weed Sci. 42:200-204.

Foley, M.E. 2008. Temperature and moisture status affect afterripening of leafy spurge (Euphorbia esula) seeds. Weed Sci. 56:237-243.

Goergen, E. and C.C. Daehler. 2001. Reproductive ecology of a native Hawaiian grass (Heteropogon contortus; Poaceae) versus its invasive alien competitor (Pennisetum setaceum; Poaceae). Intl. J. Plant Sci. 162:317-326.

Gomez, K.A. and A.A. Gomez. 1984. Statistical procedures for agricultural research. John Wiley \& Sons, New York, NY.

Iglesias-Fernandez, R., M.D. Rodriguez-Gacio, and A.J. Matilla. 2011. Progress in research on dry afterripening. Seed Sci. Res. 21:69-80.

ISTA. 1996. International rules for seed testing. Rules 1996. Seed Sci. and Technol. 24(suppl.):335.

Kew Royal Botanic Gardens. 2014. Seed Information Database (SID). Version 7.1. 6 Aug. 2014. $<$ http://data.kew.org/sid/>.

Leopold, A.C., R. Glenister, and M.A. Cohn. 1988. Relationship between water content and afterripening in red rice. Physiol. Plant. 74:659-662.

Pagano, M. and K. Gauvreau. 2000. Principles of biostatistics. Duxbury/Thomson Learning, Pacific Grove, CA.

Pater, M.J. 1993. 'Rocker' tanglehead (Heteropogon contortus [L.] Beauv. ex Roem. and J.A. Schultes): An improved cultivar for conservation. Proc. Wildland Shrub and Arid Land Restoration Symp. p. 359-360.

Pendleton, R.L., B.K. Pendleton, S.E. Meyer, S. Carlson, and E. Morrison. 2012. Viability of blackbrush seed [Coleogyne ramosissima Torr. (Rosaceae)] following long-term storage. Native Plants J. 13:5-13. 
Peters, J. 2000. Tetrazolium testing handbook. Assn. of Offic. Seed Analysts, Lincoln, NE.

Probert, R.J. 2000. The role of temperature in the regulation of seed dormancy and germination, p. 261-292. In: Fenner, M. (ed.). Seeds. The ecology of regeneration in plant communities. CABI Publishing, Oxon, UK.

Reddy, L.V., R.J. Metzger, and T.M. Ching. 1985. Effect of temperature on seed dormancy of wheat. Crop Sci. 25:455-458.

Reeve, J. and B. Strom. 2004. Statistical problems encountered in trapping studies of Scolytids and associated insects. J. Chem. Ecol. 30:15751590.

Roberts, E.H. 1988. Temperature and seed germination, p. 109-132. In: Long, S.P. and F.I. Woodward (eds.). Plants and temperature. The Company of Biologists Limited, Cambridge, UK.

Sileshi, G.W. 2012. A critique of current trends in the statistical analysis of seed germination and viability data. Seed Sci. Res. 22:145-159.

Simpson, G.M. 1990. Seed dormancy in grasses. Cambridge Univ. Press, Cambridge, UK.
Steadman, K.J., A.D. Crawford, and R.S. Gallagher. 2003. Dormancy release in Lolium rigidum seeds is a function of thermal after-ripening time and seed water content. Funct. Plant Biol. 30:345352.

Stroup, W.W. 2013. Generalized linear mixed models: Modern concepts, methods and applications. CRC Press, Boca Raton, FL.

Tarasoff, C.S., D.A. Ball, and C.A. Mallory-Smith 2007. Afterripening requirements and optimal germination temperatures for Nuttall's alkaligrass (Puccinellia nuttalliana) and weeping alkaligrass (Puccinellia distans). Weed Sci. 55:36- 40.

Toole, E.H. 1950. Relation of seed processing and of conditions during storage on seed germination. Proc. of the Intl. Seed Testing Assn. 16:214-227.

Tothill, J.C. 1968. Variation and apomixis in Heteropogon contortus, Graminae. Boletin de la Sociedad Argentina de Botanica 12:188201.
Tothill, J.C. 1977. Seed germination studies with Heteropogon contortus. Austral Ecol. 2:477-484.

Turner, S.R., D.J. Merritt, M.S. Renton, and K.W Dixon. 2009. Seed moisture content affects afterripening and smoke responsiveness in three sympatric Australian native species from fireprone environments. Austral Ecol. 34:866-877.

USDA-NRCS. 2007. Tanglehead Heteropogon contortus (L.) P. Beauv. ex. Roem. \& Schult. Plant Fact Sheet. U.S. Dept. Agr.-Natural Resources Conservation Serv. 18 Dec. 2009. <http:// plants.usda.gov/factsheet/pdf/fs_heco10.pdf > .

Wagner, W.L., D.R. Herbst, and S.H. Somer. 1999. Manual of flowering plants of Hawaii. Univ. of Hawaii Press, Honolulu, HI.

Willenborg, C.J., J.C. Wildeman, A.K. Miller, B.G. Rossnagel, and S.J. Shirtliffe. 2005. Oat germination characteristics differ among genotypes, seed sizes, and osmotic potentials. Crop Sci. 45:2023-2029.

Winston, P.W. and D.H. Bates. 1960. Saturated solutions for the control of humidity in biological research. Ecol. 41:232-237. 